\title{
Challenges for the operational detection of mountain pine beetle green attack with remote sensing
}

\author{
by Michael A. Wulder ${ }^{1,2}$, Joanne C. White ${ }^{1}$, Allan L. Carroll1 and Nicholas C. Coops ${ }^{3}$
}

\begin{abstract}
Mountain pine beetle infestations are spatially correlated; current (green) attack is often located near previous (red) attack. This spatial correlation between the green and red attack stages enables operational survey methods, as detection of red attack trees-typically from an airborne survey such as a helicopter GPS survey or aerial photography-guides the location of subsequent ground surveys for green attack trees. Forest managers, in an attempt to understand beetle movement and infestation patterns, hope to utilize remotely sensed data to detect and map green attack trees, with the expectation that the spatial extent, accuracy, and timeliness afforded by remotely sensed data will greatly improve the efficacy of beetle treatment and control. In this communication, we present the biological, logistical, and technological factors that limit the operational utility of remotely sensed data for green attack detection and mapping. To provide context for these limitations, we identify the operational information needs associated with green attack and discuss how these requirements dictate the characteristics of any potential remotely sensed data source (e.g., spatial, spectral, and temporal characteristics). Based upon our assessment, we conclude that the remote detection of green attack is not operationally viable, and is unlikely to become so unless the limiting factors we have identified are altered substantially or removed.
\end{abstract}

Key words: green attack, remote sensing, operational, insect survey, high spatial resolution, high spectral resolution

\section{RÉSUMÉ}

Les infestations de dendroctones du pin ponderosa démontrent une corrélation spatiale : l'attaque courante (verte) est souvent localisée à proximité de lattaque précédente (rouge). Cette corrélation spatiale entre les périodes vertes et rouges permet l'utilisation de méthodes de relevé opérationnelles, compte tenu que la détection d’arbres rouges attaquéshabituellement à partir d'un relevé par voie aérienne par exemple effectué au moyen d'un GPS monté à bord d'un hélicoptère ou par photos aériennes-indique la localisation des relevés terrestres à venir des arbres verts attaqués. Les aménagistes forestiers, cherchant à comprendre le déplacement des dendroctones et les patrons d'infestation, souhaitent utiliser les données obtenues par télédétection afin d'identifier et de cartographier les arbres verts attaqués, avec l'espoir que la distribution et la précision dans le temps et l'espace permises par les données de télédétection permettront de grandement améliorer lefficacité du traitement et du contrôle du dendroctone. Nous présentons dans ce texte les facteurs biologiques, logistiques et technologiques qui limitent l'utilité opérationnelle des données de télédétection dans le cas de la détection et la cartographie des attaques vertes. Afin d'illustrer le contexte de ces limites, nous identifions les besoins requis en matière d'information opérationnelle associée à une attaque verte et nous discutons comment ces besoins dictent les caractéristiques de toute source potentielle de données acquises par télédétection (par ex., caractéristiques spatiales, spectrales et temporelles). En fonction de notre évaluation, nous concluons que la télédétection d'une attaque verte n'est pas viable en terme opérationnel et qu'il est improbable quelle le devienne à moins que les facteurs que nous avons identifiés soient substantiellement modifiés ou annulés.

Mots clés : attaque verte, télédétection, niveau opérationnel, relevé d'insectes, haute résolution spatiale, haute résolution spectrale

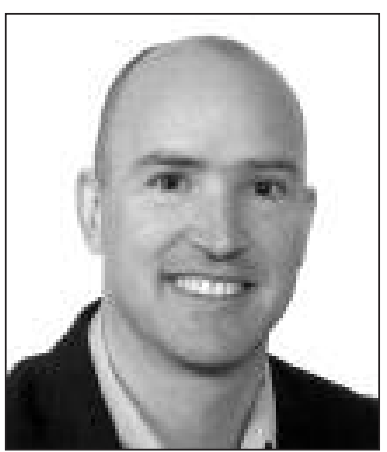

Michael A. Wulder

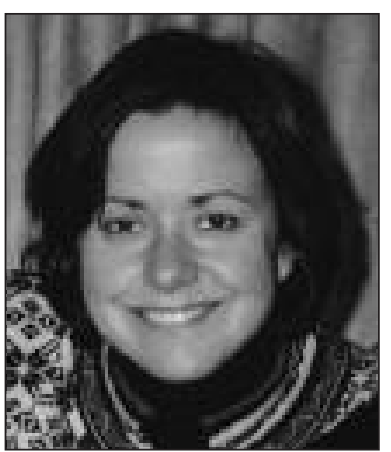

Joanne C. White

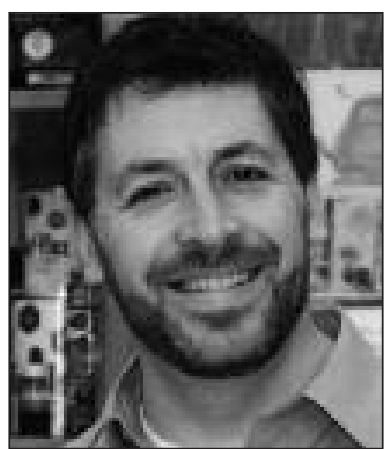

Allan L. Carroll

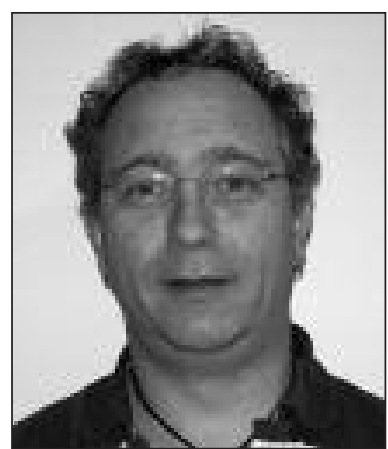

Nicholas C. Coops

\footnotetext{
${ }^{1}$ Canadian Forest Service (Pacific Forestry Centre), Natural Resources Canada, 506 West Burnside Road, Victoria, British Columbia V8Z 1M5.

${ }^{2}$ Corresponding author. E-mail: mwulder@nrcan.gc.ca

${ }^{3}$ Department of Forest Resource Management, 2424 Main Mall. University of British Columbia, Vancouver, British ColumbiaV6T 1Z4.
} 


\section{Introduction}

Mountain pine beetle (Dendroctonus ponderosae Hopkins) has infested more than 13 million ha of pine forest in western Canada since 1999 (Raffa et al. 2008) and has been the leading cause of forest mortality in British Columbia for many years (Westfall and Ebata 2008). To date, total cumulative volume losses associated with the current outbreak in British Columbia are estimated at 620 million $\mathrm{m}^{3}$, representing $46 \%$ of the total merchantable pine volume on British Columbia's timber harvesting land base (Walton et al. 2008). The magnitude of the current mountain pine beetle outbreak has converted the forest in the impacted area from a small net carbon sink to a large net carbon source (Kurz et al. 2008).

Alterations in established climatic limitations to mountain pine beetle survival (Réginière and Bentz 2007, Aukema et al. 2008, Raffa et al. 2008) and an abundance of suitable hosts (typically Pinus contorta) have contributed to this current population increase and the associated spread of the beetle into geographic regions not conventionally host to large populations of mountain pine beetle (Taylor et al. 2006). Typical mountain pine beetle monitoring and mitigation scenarios are informed by airborne platforms that identify foliar discoloration indicative of successful attack (red attack) and guide ground surveys to locate currently attacked trees (green attack) in a systematic manner (Wulder et al. 2006b). These green attack trees may then be subject to treatment, which is often a fall-and-burn process where trees are felled, cut into sections and burned. Successful brood development and subsequent flight is prevented through such scenarios (Carroll et al. 2006).

The use of new technologies for forest measurement and monitoring (i.e., GPS, digital photography, laser hypsometers, digital data loggers) have increased measurement accuracy and reduced costs. Digital remote sensing has likewise provided many unique opportunities for forest measurement and monitoring, enabling synoptic measurements of landscape level conditions over large areas (e.g., >100 $000 \mathrm{ha}$ ), or conversely, detailed measurements of stand- or tree-level characteristics over small areas (e.g., $<10000 \mathrm{ha}$ ). In some cases, operational and biological limitations can constrain the utility of a well-established remote sensing approach. Furthermore, when the technology itself is unproven and untested, operational implementation is not viable. In this communication we describe the limiting circumstances for the remotely sensed measurement of the pre-visual (green attack) stage of mountain pine beetle infestation.

There is interest in the forest management community in using new technologies such as remote sensing to directly capture the location and extent of green attack trees. The expectation is that such efforts would increase the spatial extent, timeliness, and accuracy of green attack detection over that of existing ground survey methods, thereby greatly improving the efficacy of beetle treatment and control-particularly at the leading edge of an infestation. However, many biological, logistical, and technological factors exist that limit the utility of remotely sensed data for green attack detection. In this communication we discuss these limiting factors and present the operational criteria (e.g., spatial extent, time of year, data turnaround) that dictate the required characteristics of remotely sensed data (e.g., spatial, spectral, and temporal) intended for such an application.

\section{Background}

\section{Mountain pine beetle biology}

The mountain pine beetle feeds and reproduces within the phloem tissues beneath the bark of its host trees (most species of pine). In the process of colonization, the beetle also vectors phytopathogenic blue-stain fungi. The combination of beetle feeding and fungal development disrupts the translocation of water, sugar and other nutrients within the bole of a tree (Safranyik and Carroll 2006). Restricted water and nutrient conductance to the crown ultimately leads to foliar cell death and disruption of pigments. As a result, foliage fades from green to yellow to red. The green attack stage is that period of time immediately following successful mountain pine beetle attack, but before symptoms of attack are visibly evident in the crown (i.e., before fading can be detected with the eye). The onset of visible symptoms of crown fading is highly variable and depends on a number of factors such as timing of attack during the year, attack density, tree vigour, soil moisture, and weather conditions. Normally, in western Canada the first symptoms of fading occur in late May to early June of the year after attack. However, following hot, dry weather during late summer and early fall, faded crowns may be visible during autumn of the year of attack (Safranyik and Carroll 2006). Although the onset of fading may be highly variable, it is typically complete within a year of the original attack as trees enter the red attack stage (Wulder et al. 2006b). The duration of the red attack stage is also variable, and red attack trees may retain their needles for several years (3 to 5 years for lodgepole pine (Safranyik and Carroll 2006); therefore, it is difficult to reliably use crown symptoms to estimate the timing of tree death (Safranyik et al. 1974). Once needles have been shed from the dead trees, they are considered to be in the grey attack stage.

\section{Operational information needs}

Forest managers need to know the number and location of green attack trees in order to strategically and operationally allocate resources for mitigation and control, to indicate rates of population change (when compared to the number of infested trees from the previous year and to assess whether there is an influx of beetles from other areas), and to determine the timing of control activities (i.e., infested trees must be removed before brood emergence and flight). Since green attack trees are those that contain the next generation of beetles (i.e., the developing broods), successful control programs are contingent upon detection and removal of these trees prior to beetle emergence and dispersal.

The government agencies responsible for forest management in the provinces of British Columbia and Alberta partition beetle infested areas into 3 broad strategic zones: aggressive management (leading-edge), containment (holding), and salvage (British Columbia Ministry of Forests and Range 2007a, Alberta Sustainable Resource Development 2007a). In British Columbia, each of these broad zones is further subdivided into several smaller operational beetle management units (BMUs), which are used to allocate finite resources for suppression activities, as well as for planning and reporting purposes (British Columbia Ministry of Forests and Range 2007a). On an annual basis, the status of the BMUs is assessed, and each is assigned 1 of 4 different management strategies (i.e.,suppress, hold, salvage, or monitor) based on 
the severity and extent of the infestation, as depicted in the most current aerial overview survey data. Most of the BMUs found within the aggressive management zone have a suppression strategy. In Alberta, management practices are inherent to the 3 broadly defined zones, with prescribed treatments appropriate for the severity of the infestation (Alberta Sustainable Resource Development 2007b).

One of the key information needs required for assigning a management strategy to a BMU is the rate of increase of a beetle population, which is determined by estimating the ratio of currently attacked trees (green attack) to 1-year-old attacked (red attack) trees (G:R). Typically, a BMU is stratified by susceptibility class (i.e., high, moderate, low), and a subsample of 10 to 15 stands from each stratum are strip-surveyed. The number of green attack and red attack trees are enumerated for each strip survey and then averaged for the BMU (British Columbia Ministry of Forests 2001a). Preexisting ground survey data may similarly be used to estimate G:R. A G:R greater than 1 is indicative of an increasing population, while a $\mathrm{G}: \mathrm{R}$ less than 1 is indicative of a declining population.

At the commencement of the current infestation, before the extent of the damage is widespread, aggressive control tactics are being implemented on the leading edge of the infestation. Under this practice, susceptible stands are harvested before they experience epidemic levels of infestation, and knowledge of the location and extent of green attack is critical for identifying where the leading edge is located. Typically, ground surveys are conducted in the fall and winter, with mitigation occurring in the very early spring. Again, this is partly driven by biology and the need to remove the trees before the brood emerge and fly, but also logistical as the government fiscal year ends by March 31 and any funds allocated for mitigation in that fiscal year must be spent prior to that date (British Columbia Ministry of Forests and Range 2007b). Follow-up surveys may be conducted in treated areas to assess the efficacy of mitigation practices, by determining whether the G:R is increasing, decreasing, or stable. In Alberta, operational ground rules and harvesting methods vary according to whether or not there is green attack present in the stand (Alberta Sustainable Resource Development 2006b, 2006b). In British Columbia, a similar approach is followed under the Bark Beetle Regulation of the Forest Practices Code (British Columbia Ministry of Forests 2001b).

\section{Ground Assessment of Green Attack}

Survey of green attack is typically achieved by capitalizing on an understanding of mountain pine beetle biology and spread, whereby most beetles infest trees near their emergence location. Safranyik et al. (1992) conducted a detailed markrelease-recapture study within a mature lodgepole pine forest, recapturing an average of $25 \%$ of the beetles they released. Of these, they found that the number of beetles recaptured decreased exponentially with increasing distance from the release point; approximately $90 \%$ of beetles were captured within $30 \mathrm{~m}$ of their release location. Moreover, less than $2.5 \%$ of beetles were considered to have attempted long-distance dispersal above the canopy and out of the stand. The likelihood that green attack trees are located near red attack trees has enabled a hierarchical monitoring approach to be implemented.
This hierarchical approach begins with a broad scale (i.e., at $1: 100000$ to $1: 250000$ scale) visual interpretation of mountain pine beetle attack (among other forest health issues), undertaken annually on a province-wide basis (aerial overview survey) (British Columbia Ministry of Forests 2000). These broad-scale depictions of mountain pine beetle attack are integrated with regionally specific information on forest composition and structure, and information from surveys in previous years (Wulder et al. 2006c). This information aids forest managers in determining if suppression is possible and if the collection of additional, more detailed data is worthwhile. If it is deemed that further information would prove useful from a management, monitoring, or mitigation point of view, the information is then collected. Detailed information on tree-level red attack status is available to forest managers through helicopter-based Global Positioning System (heliGPS) surveys or, in some cases, from the interpretation of larger-scale photography or imagery. Heli-GPS is the more common approach for single tree depictions, providing information rapidly with operationally useful levels of accuracy to aid in management and mitigation activities (Nelson et al. 2006). The tree counts and locations that are provided to forest managers by the heli-GPS survey enable prioritization, planning, and implementation of management plans. Ground crews are dispatched to locations where red attack trees are present, and follow a systematic protocol for sanitation of colocated green attack stage trees (Wulder et al. 2004).

Two additional types of surveys are also often undertaken in the field: post-flight ground surveys and over-wintering brood mortality assessments. The timing of these survey activities is important. Post-flight ground surveys must occur, as the name suggests, post-flight and post-colonization (if surveys are undertaken too early in the summer, beetle flight and colonization may be missed). Appropriate timing of postflight surveys will depend on local conditions and completion of aerial surveys (British Columbia Ministry of Forests 2000, Wulder et al. 2006b), in order to capture the greatest amount of the impact occurring that year. Ground surveys enable accurate estimates of the $G$ : $R$ ratio by directly quantifying the number of green attack trees based on evidence of fresh beetle attacks, and determining the number of red attack trees from the previous year through visual assessments of crown conditions and examination of conditions beneath the bark (i.e., presence/absence of moist phloem).

The assessment of brood over-wintering mortality is conducted in late winter and early spring and aids in determining the trend of the infestation for that current year. The characteristics observed to inform on brood over-wintering mortality include number of progeny (larvae/pupae) and the number of parental galleries begun per $900 \mathrm{~cm}^{2}$ of phloem area. This information allows for the calculation of the r-value, which produces information regarding the trend in infestation level for current year (Carroll et al. 2006). This assessment of the state of populations through the calculation of an $r$-value in early spring is a critical metric, and when combined with $\mathrm{G}: \mathrm{R}$ ratios, may be used to determine the proportion of beetles that were immigrants versus locals, as well as the size of the population for the next flight period (Carroll 2007).

Precise information on location and number of trees requiring treatment is critical to successful mitigation activities. In addition to post-flight and over-wintering mortality 
assessments, ground-based surveys can generate 2 other important sources of information essential to control efforts. First, they enable determination of the agent responsible for tree death. In a lodgepole pine forest there are many potential sources of tree mortality that can be confused with a small mountain pine beetle infestation such as root pathogens, localized fluctuations in water tables, as well as several other bark beetle species (Safranyik and Carroll 2006). Second, direct assessment of stand conditions during surveys can be used to augment forest inventory databases and facilitate accurate calculations of stand susceptibility (Shore and Safranyik 1992) and other potentially important attributes such as connectivity to susceptible yet uninfested pine forests. Given the typically limited resources and time within a season in which to mount mitigation programs, priority must be given to the treatment of those infestations with the highest probability of increase and spread (Carroll et al. 2006). Ground surveys are undertaken judiciously due to their high per-hectare cost. Aerial surveys conducted for red attack detection have the advantages of lower cost per hectare and reliable recognition of the damage agent (Wulder et al. 2006a).

\section{Remote Assessment of Green Attack}

Detection of mountain pine beetle red attack has been demonstrated with a range of remotely sensed data sources (Skakun et al. 2003; White et al. 2005, 2007; Coops et al. 2006; Wulder et al. 2006b, 2008); however, the successful detection of green attack trees with remotely sensed data has not been documented in the literature. Researchers have attempted to use aerial photography to detect green attack trees-Murtha (1972) used 1:1000 ( 1 inch $=1000$ feet) colour infrared air photos to examine the spectral reflectance from 2 non-attack trees, 6 green attack trees, and 4 red attack trees, concluding that the differences in the spectral responses of these trees were attributable to their attack stage. Subsequent studies have had difficulty distinguishing green attack tree crowns from non-attack tree crowns using high-resolution air photos, as a result of the variability and overlap in the spectral signals from green attack and non-attack crowns (Murtha and Wiart 1989a, b). While aerial photography has been successful for mapping individual trees with red attack damage (e.g., Klein 1973, Gimbarzevsky et al. 1992) research aimed at green attack detection has been inconclusive.

Ahern (1988) measured the spectral response of lodgepole pine foliage of both mountain pine beetle green attack and unattacked trees and identified specific wavelength ranges where the spectral difference between the foliage of the green attack and unattacked trees was greatest (Table 1). Ahern (1988) identified the age of the foliage as an important factor in discriminating green attack and therefore considered both the age of the foliage (i.e., current and old foliage) and attack status simultaneously. At the green attack stage, it is primarily in the visible and near infrared (NIR) portions of the spectrum where the spectral differences have been documented (Heller 1968; Ahern 1988; Murtha and Wiart 1987, 1989a). Of those areas of the spectrum identified by Ahern (1988), the greatest difference was in the NIR (730-760nm), with a highly significant difference also found in the NIR plateau (720-1050nm). Heller (1968) identified spectral difference similar to those of Ahern (1988) for the pre-visual detection of bark beetle attack in Ponderosa pine trees in South Dakota.
Table 1. Documented spectral responses for green attack foliage (adapted from Ahern 1988)

\begin{tabular}{ll}
$\begin{array}{l}\text { Wavelength } \\
\text { Range (nm) }\end{array}$ & Reflectance behaviour \\
\hline $525-565$ & $\begin{array}{l}\text { Lower for current foliage in attacked trees. } \\
633\end{array}$ \\
$\begin{array}{l}\text { Higher for current foliage of attacked trees. } \\
690-730\end{array}$ & $\begin{array}{l}\text { Red shifted for current foliage of attack trees. } \\
\text { Lower for attacked trees, statistically more signifi- } \\
\text { cant than remainder of IR plateau. }\end{array}$ \\
$760-1050$ & Lower for attacked trees. \\
\hline
\end{tabular}

As the tree's foliage becomes increasingly desiccated and the tree enters the red attack stage, changes in foliage moisture (as captured in the shortwave infrared portion of the electromagnetic spectrum) are more useful for discriminating attack (White et al. 2007). Ahern (1988) concluded that the separability between green attack and unattacked trees in these identified spectral regions may not be as great when the whole tree and background elements are considered. Similarly, Puritch (1981) found poor detection of pre-visual symptoms of stress when the data integrate foliage, branches, and other background elements common to forests. Murtha and Wiart (1989b) found that non-attacked tree crowns had more spectral variability than green attack tree crowns.

Heath (2001) attempted to use the Compact Airborne Spectrographic Imager (CASI), a hyperspectral instrument, to detect green attack and found considerable overlap in the spectral response of green and unattacked lodgepole pine. In direct contrast to the strong visual and spectral response associated with red attack damage, the natural variability inherent in the spectral response of healthy lodgepole pine complicates the previsual detection of mountain pine beetle attack (Heath 2001). This natural variability is further complicated by the effects of factors such as other insects, root rot, fungi, and drought, all of which can generate a pre-visual change in spectral response similar to that of green attack (Safranyik et al. 1975, Henigman et al. 1999, Vollenweider and Günthardt-Goerg 2005).

\section{Limits to Remote Assessment of Green Attack}

There are many biological, logistical, and technological factors that may limit the utility of using remotely sensed data to detect and map green attack.

\section{Biological}

Biological considerations are primarily related to the timing of specific phenomena (i.e., the timing of beetle flight, the length of time required for gallery development and blue stain fungi inoculation, and the time required for the resulting previsual expression of the attack to develop in the tree crowns). The fading of the foliage in the crown of a tree infested with mountain pine beetle is not a consistent, linear process and depends upon tree genetics, tree condition, and the local environment (Safranyik et al. 1974). The variability in fade rates (i.e., the rate at which the foliage changes colour) caused by climate and phenology is of critical importance to the detection of mountain pine beetle damage via remotely sensed data. Fig. 1 depicts the general trend in fade rates over 
time, where the fading of 15 lodgepole pine trees at a specific site is followed over 3 years, with the overlap between the tree crown expressions of attack stages illustrated. It is important to note that the variability in the rate of fading is even greater than what is depicted in Fig. 1 over larger areas, where there is more variability in tree characteristics and environmental conditions (Safranyik and Carroll 2006, Wulder et al. 2006b).

\section{Logistical}

Logistically, timing plays a critical role in any remotely sensed survey of green attack, as it does for ground surveys, with due consideration being given to the temporal issues associated with beetle biology and the manifestation of the pre-visual symptoms in the tree foliage. However, unlike ground surveys, remotely sensed surveys of green attack are further constrained by timing issues associated with optimal conditions required for image acquisition. For example, capture of imagery outside of the photosynthetically active summer months will result in reduced solar isolation, limiting the available spectral signal (a weak spectral signal can limit spectral differentiation between healthy and green attack trees). Moreover, at more northerly latitudes, lower sun angles and shorter days further limit the available image acquisition window. Drought stress or snow accumulation can similarly impact image quality and must also be considered. The earlier the detection of attack is attempted, the higher the omission rate of actual attacked trees is likely to be; conversely, the longer detection is delayed, the more likely early fading will be evident (precluding the need for pre-visual green attack detection). To demonstrate the variability of fade rates and the associated implications for detection, Roberts et al. (2003) collected a time series of airborne images between April and October of 2002 in 6 different sample locations. The imagery indicated that attacked trees will fade at different rates, even in the same location.

A remotely sensed survey designed to detect and map green attack must therefore be scheduled with consideration of the approximate date of beetle flight, the period of time required for the attack to manifest pre-visual symptoms (based on gallery development and blue stain fungi inoculation-but before damage is visible), the site conditions that may speed or slow the aforementioned factors, and finally, the solar illumination conditions that enable the acquisition of imagery of sufficient quality to be useful for spectral differentiation between healthy trees and green attack trees. All of these timing factors must serendipitously coincide with favourable weather conditions (e.g., cloud free conditions) that enable image collection via satellite or from an airborne platform. Operational surveys of green attack must collect imagery over large areas where there is a high likelihood of beetle infestation (i.e., a large proportion of pine), but where no current infestation exists (as indicated by red attack damage). If red attack damage is already present in an area, there is no need for early detection of the infestation, as the likelihood that green attack trees will be found in the area is very high.

\section{Technological}

Technologically, the information needs associated with green attack necessitate the use of remotely sensed data with both a high spatial and high spectral resolution. Spatially, individual (ideally sunlit, not shaded) tree crowns need to be represented by multiple pure pixels in order to have a strong spectral (and primarily foliar) response that is not diluted by background image elements such as branches, understorey, or ground. Spectrally, the data must be sensitive enough in the appropriate wavelength ranges of the electromagnetic spectrum where the subtle spectral differences associated with green attack are greatest and may be discerned.

Currently, there is no commercially available satellite sensor that can satisfy both the spatial and spectral parameters required for successful green attack detection. Airborne remote sensing can provide data with both high spatial and spectral resolution; however, the combination of spatial and spectral resolution offered by airborne platforms are typically the result of a series of trade-offs. For instance, smaller pixels require the aircraft to fly low and slow, with subsequently narrow flight swaths; a sensor with 512 detectors across track and a spatial resolution of $50 \mathrm{~cm}$, will produce a swath approximately $200 \mathrm{~m}$, necessitating the collection of many flight lines if large area coverage is desired. This requirement for a large number of images further increases the complexity of the image processing (georeferencing, mosaicking, absolute reflectance correction) and also increases costs. Moreover, as line-to-line spectral conditions typically vary across scenes, images require normalization, resulting in a reduction in the overall variance of the spectral values, and impacting the subsequent power of detection algorithms. Whilst some research has been undertaken using airborne spectrometers, such as CASI, to detect and map green attack, results thus far have been inconclusive (Heath 2001, Roberts et al. 2003).

In summary, a remote sensing conundrum emerges with the pursuit of green attack. In order for remotely sensed sur- 
veys of green attack to be useful in a management context, large areas need to be surveyed, detection accuracy must be very high, errors of commission must be low, and survey costs must be low relative to costs for established ground survey methods. Image processing and information on green attack must be generated rapidly and provided to forest managers before fade begins in order to facilitate the early deployment of mitigation crews-otherwise, forest managers could continue to rely on existing, low-cost methods of red attack detection, with green attack located by spatial association. Finally, the forest management intentions must also be considered. If complete sanitation (i.e., removal of all detected green attack trees) is not anticipated, or not possible due to limited resources, it may be more cost-effective to continue to co-locate green attack trees based on the detection of red attack trees; at this time, detection of red attack can be done with greater accuracy, lower costs, and over a longer time window. Furthermore, detection can focus on areas where beetle populations are developing and acting as a sourcerather than expending scarce resources over larger areas with the aim to eradicate single trees or small groups of attacked trees that may not have the potential (based on forest or environmental conditions) to spread or increase beetle population levels. Moreover, in the absence of an explicit management intention to conduct broad-scale sanitation, organizational will, and/or sufficient funds to act upon green attack information, identification and mitigation based upon red attack surveys and associated procedures will generally prove sufficient.

\section{Conclusions}

Interest has been expressed by the forest management community in the use of remotely sensed data to detect and map green attack trees, with the expectation that the advantages afforded by remotely sensed data would greatly improve the efficacy of beetle treatment and control. In this communication we describe the operational information needs associated with mountain pine beetle green attack and in this context, identify those factors that limit the use of remotely sensed data for green attack detection and mapping. Consideration is given to a range of biological (e.g., beetle flight, gallery development and blue stain fungi inoculation period, variable fade rates, and resulting expression of the attack in tree crown), logistical (e.g., low sun angles, possible snow cover, large area coverage required, need to collect imagery when there is previsual foliar expression, but prior to fading, with consideration of biological criteria), and technological factors, including complexities and costs of data acquisition and processing, and availability of funds for follow-up sanitation. Over time, some of the technological issues identified will likely be overcome through innovation and research; however, in the short-term, the recognition of these limitations enables identification of research gaps and opportunities for further investigation. Given the disjoint between the information needs associated with green attack detection and the range of limitations associated with the use of remotely sensed data for this purpose, we conclude that the use of remotely sensed data is not operationally viable for the detection and mapping of the green attack stage of mountain pine beetle infestation. Furthermore, the remote detection of green attack is unlikely to become viable unless the constraints we have identified are substantially altered or removed.

\section{Acknowledgements}

This project was funded by the Government of Canada through the Mountain Pine Beetle Program administered by Natural Resources Canada, Canadian Forest Service (for more information see http://mpb.cfs.nrcan.gc.ca/).

\section{References}

Alberta Sustainable Resource Development. 2006a. Ground rules addendum - mountain pine beetle operations. Available at http://www.srd.gov.ab.ca/forests/pdf/MPB\%20OGR\%20Addendum_march\%2015_07.pdf [Accessed April 2, 2008].

Alberta Sustainable Resource Development. 2006b. Mountain pine beetle management guide. Available at http://www.srduatnew. gov.ab.ca/forests/health/publications/mpbmanagement.aspx [Accessed April 2, 2008].

Alberta Sustainable Resource Development. 2007a. Mountain pine beetle management strategy. Pub No. T/154. Available at http://www.srd.gov.ab.ca/forests/pdf/MPB_man_strategy.pdf [Accessed April 2, 2008].

Alberta Sustainable Resource Development. 2007b. Mountain pine beetle action plan. Pub No. T/152. Available at http://www.srd. gov.ab.ca/forests/pdf/MPB_action_plan.pdf [Accessed April 2, 2008].

Ahern, F. J. 1988. The effects of bark beetle stress on the foliar spectral reflectance of lodgepole pine. International Journal of Remote Sensing 9: 1451-1468.

Aukema, B.H., A.L. Carroll, Y. Zheng, J. Zhu, K.F. Raffa, D. Moore, K. Stahl and S.W. Taylor. 2008. Movement of outbreak populations of mountain pine beetle: influences of spatiotemporal patterns and climate. Ecography 31: 348-358.

British Columbia Ministry of Forests. 2000. Forest Health Aerial Overview Survey Standards for British Columbia, version 2.0. Forest Practices Branch and the Canadian Forest Service, Victoria, BC. 48 p. British Columbia Ministry of Forests. 2001a. How to estimate green:red. Forest Practices Branch, Victoria, British Columbia. Available at http://www.for.gov.bc.ca/hfp/health/fhdata/green_ to_red.htm [Accessed April 2, 2008].

British Columbia Ministry of Forests. 2001b. Bark beetle regulation. Available at http://www.for.gov.bc.ca/tasb/legsregs/archive/ fpc/fpcaregs/barkbeet/bbr.htm\#7-1 [Accessed April 2, 2008].

British Columbia Ministry of Forests and Range. 2007a. Provincial bark beetle management technical implementation guidelines: August 2007. Forest Practices Branch, Victoria, British Columbia. Available at http://www.for.gov.bc.ca/hfp/health/fhdata/bbstrategy. htm [Accessed April 2, 2008].

British Columbia Ministry of Forests and Range. 2007b. Forest District MPBI Updates. Available at http://www.for.gov.bc.ca/hfp/ mountain_pine_beetle/ColumbiaUpdate.pdf, http://www.for.gov. bc.ca/hfp/mountain_pine_beetle/HeadwatersUpdate.pdf, http://www.for.gov.bc.ca/hfp/mountain_pine_beetle/RockyMountainUpdate.pdf, and http://www.for.gov.bc.ca/hfp/mountain_pine_ beetle/PeaceUpdate.pdf [Accessed April 2, 2008].

Carroll, A.L. 2007. The mountain pine beetle Dendroctonus ponderosae in western North America: Potential for area-wide integrated management. In M.J.B. Vreysen, A.S. Robinson and J. Hendricks (eds.). Area Wide Control of Insect Pests: From research to field implementation. pp. 297-307. Springer, Netherlands. 792 p.

Carroll, A.L., T.L. Shore and L. Safranyik. 2006. Direct control: Theory and practice. (Chapter 6). In L. Safranyik and W.R. Wilson (eds.). The mountain pine beetle: a synthesis of biology, management, and impacts on lodgepole pine. pp. 155-172. Natural Resources Canada, Canadian Forest Service, Pacific Forestry Centre, Victoria, BC. 304 p.

Coops, N.C., M. Johnson, M.A. Wulder and J.C. White. 2006. Assessment of QuickBird high spatial resolution imagery to detect red-attack damage due to mountain pine beetle infestation. Remote Sensing of Environment 103: 67-80. 
Gimbarzevsky, P., A.F. Dawson and G.A. Van Sickle. 1992. Assessment of aerial photographs and multi-spectral scanner imagery for measuring mountain pine beetle damage. Forestry Canada, Victoria, BC. Information Report, BC-X-333. 31 p.

Heath, J. 2001. The Detection of Mountain Pine Beetle Green Attacked Lodgepole Pine Using Compact Airborne Spectrographic Imagery (CASI) Data, M.Sc. thesis, Faculty of Forestry, University of British Columbia, BC. 72 p.

Heller, R.C. 1968. Pre-visual detection of ponderosa pine trees dying from bark beetle attack. In Proceedings of the $5^{\text {th }}$ International Symposium of Remote Sensing of Environment. pp. 387-418. Ann Arbor, MI.

Henigman, J., T. Ebata, E. Allen, J. Holt and A. Pollard (eds.). 1999. Field Guide to Forest Damage in British Columbia. British Columbia Forest Service and Canadian Forestry Service Joint Report \# 17. Ministry of Forests, Victoria, BC. 348 p.

Klein, W.H. 1973. Beetle-killed pine estimates. Photogrammetric Engineering 39: 385-388.

Kurz, W.A., C.C. Dymond, G.G. Stinson, G.J. Rampley, E.T. Neilson, A.L. Carroll, T. Ebata and L. Safranyik. 2008. Mountain pine beetle and forest carbon feedback to climate change. Nature 452: 987-990. Murtha, P. 1972. A guide to air photo interpretation of forest damage in Canada. Canadian Forestry Service, Ottawa. Publication No.1292. 62 p.

Murtha, P. and R.J. Wiart. 1987. PC-based digital image analysis for mountain pine beetle green attack: preliminary results. Canadian Journal of Remote Sensing 13: 92-95.

Murtha, P. and R.J. Wiart. 1989a. PC-based digital analysis of mountain pine beetle current-attacked and non-attacked lodgepole pine. Canadian Journal of Remote Sensing 15: 70-76.

Murtha, P. and R.J. Wiart. 1989b. Cluster analysis of pine crown foliage patterns aid identification of mountain pine beetle currentattack. Photogrammetric Engineering and Remote Sensing 55: 83-86. Nelson, T., B. Boots and M.A. Wulder. 2006. Representing Large Area Mountain Pine Beetle Infestations. The Forestry Chronicle 82 243-252.

Puritch, G.S. 1981. Non-visual remote sensing of trees affected by stress: A review. Environment Canada, Canadian Forestry Service, Pacific Forest Research Centre, Victoria, BC. Information Report BC-X-30. 38 p.

Raffa, K.F., B.H. Aukema, B.J. Bentz, A.L. Carroll, J.A. Hicke, M.G. Turner and W.H. Romme. 2008. Cross-scale drivers of natural disturbances prone to anthropogenic amplification: The dynamics of bark beetle eruptions. BioScience 58: 501-517.

Réginière, J., and B. Bentz 2007. Modeling cold tolerance in the mountain pine beetle, Dendroctonus ponderosae. Journal of Insect Physiology 53: 559-571.

Roberts, A., J. Northrup, S. Wolf and Y. Li. 2003. Mountain pine beetle detection and monitoring: phase II enhancement, interpretation and evaluation of airborne imagery. Department of Geography. Simon Fraser University, Burnaby, BC. FIA Project No. 4036002. 22 p. Safranyik, L. and A.L. Carroll. 2006. The biology and epidemiology of the mountain pine beetle in lodgepole pine forests. In L. Safranyik and B. Wilson (eds.). The Mountain Pine Beetle: a Synthesis of its Biology, Management and Impacts on Lodgepole Pine. pp. 3-66. Natural Resources Canada, Canadian Forest Service, Pacific Forestry Centre, Victoria, BC. 304 p.

Safranyik, L., D.A. Linton, R. Silversides and L.H. McMullen. 1992. Dispersal of released mountain pine beetles under the canopy of a mature lodgepole pine stand. Journal of Applied Entomology 113: 441-450.

Safranyik, L., D.M. Shrimpton and H.S. Whitney. 1974. Management of lodgepole pine to reduce losses from the mountain pine beetle. Government of Canada. Department of the Environment. Canadian Forest Service, Pacific Forest Research Centre, Victoria, BC. Forestry Technical Report 1
Safranyik, L., D.M. Shrimpton and H.S. Whitney. 1975. An interpretation of the interaction between lodgepole pine, the mountain pine beetle, and its associated blue stain fungi in western Canada. In Proceedings of the Symposium on Management of Lodgepole Pine Ecosystems, Washington State University, Pullman, 9-11 October, 1973. pp. 406-428.

Shore, T.L. and L. Safranyik. 1992. Susceptibility and risk rating systems for the mountain pine beetle in lodgepole pine stands. Forestry Canada, Pacific and Yukon Region. Information Report BC-X 336.12 p.

Skakun, R.S., M.A. Wulder and S.E. Franklin. 2003. Sensitivity of the thematic mapper enhanced wetness difference index to detect mountain pine beetle red attack damage. Remote Sensing of Environment 86: 433-443.

Taylor, S.W., A.L. Carroll, R.I. Alfaro and L. Safranyik. 2006. Forest, climate and mountain pine beetle dynamics. In L. Safranyik and B. Wilson (eds.). The Mountain Pine Beetle: a Synthesis of its Biology, Management and Impacts on Lodgepole Pine. pp. 67-94. Natural Resources Canada, Canadian Forest Service, Pacific Forestry Centre, Victoria, BC. 304 p.

Vollenweider, P. and M.S. Günthardt-Goerg. 2005. Diagnosis of abiotic and biotic stress factors using the visible symptoms in foliage. Environmental Pollution 137: 455-465.

Walton, A., J. Hughes, M. Eng, A. Fall, T. Shore, B. Riel and P. Hall. 2008. Provincial-level projection of the current mountain pine beetle outbreak. Update of the infestation projection based on the 2007 provincial aerial overview of forest health and revisions to the "model" (BCMPB.v5). Available at http://www.for.gov.bc.ca/hre/ bcmpb/BCMPB.v5.BeetleProjection.Update.pdf [Accessed June 24, 2008].

Westfall, J. and T. Ebata, 2008. 2007 Summary of Forest Health Conditions in British Columbia. British Columbia Ministry of Forests, Forest Practices Branch, Victoria, BC. 81 p. Available at http://www.for.gov.bc.ca/ftp/HFP/external/!publish/Aerial_Overvie w/2007/Aerial\%20OV\%202007.pdf [(accessed June 24, 2008].

White, J.C., M.A. Wulder, D. Brooks, R. Reich and R. Wheate. 2005. Mapping mountain pine beetle infestation with high spatial resolution satellite imagery. Remote Sensing of Environment 96: 240-251.

White, J.C., N.C. Coops, T. Hilker, M.A. Wulder and A.L. Caroll. 2007. Detecting mountain pine beetle red attack damage with EO-1 Hyperion moisture indices. International Journal of Remote Sensing 28: 2111-2121.

Wulder, M.A., C.C. Dymond and B. Erikson. 2004. Detection and monitoring of the mountain pine beetle. Natural Resources Canada, Canadian Forest Service, Pacific Forestry Centre, Victoria, BC. Information Report BC-X-398. 32 p.

Wulder, M.A., C.C. Dymond, J.C. White and B. Erikson. 2006 a. Detection, mapping and monitoring of the mountain pine beetle. In L. Safranyik and B. Wilson (eds.). The Mountain Pine Beetle: A Synthesis of its Biology, Management and Impacts on Lodgepole Pine. pp. 123-154. Natural Resources Canada, Canadian Forest Service, Pacific Forestry Centre, Victoria, BC. 304 p.

Wulder, M.A., C.C. Dymond, J.C. White, D.G. Leckie and A.L. Carroll. 2006b. Surveying mountain pine beetle damage of forests: A review of remote sensing opportunities. Forest Ecology and Management 221: 27-41.

Wulder, M.A., J.C. White, B.J. Bentz and T. Ebata. 2006c. Augmenting the existing survey hierarchy for mountain pine beetle red attack damage with satellite remotely sensed data. The Forestry Chronicle 82: 187-202.

Wulder, M.A., J.C. White, N.C. Coops and C.R. Butson. 2008. Multi-temporal analysis of high spatial resolution imagery for disturbance monitoring. Remote Sensing of Environment 112: 2729-2740. 